\title{
Direct Tensile Strength in Joint of Roller Compacted Concrete Dams
}

\author{
[J. O. Morandi, R. J. Uliarte]
}

\begin{abstract}
Roller Compacted Concrete (RCC) Dam construction involves the placement of concrete in successive layers, whose thickness may vary in general between 30 and 45 $\mathrm{cm}$. The surfaces of contact between layers are planes or joints of potential weakness for the material, giving the same anisotropic mechanical characteristics. The tensile strength and shear strength of the joint between layers are basic design parameters for the RCC dam project, particularly necessary to ensure the reliability of the structure against seismic loads. The present work describes a test method to determine the direct tensile strength of the joint between layers and experimental results are obtained with this method, corresponding to the test of joints made under different conditions of concreting.The conditions studied included the test of joints with and without cement mortar, made with different waiting times between layers. Waiting times were one minute (continuous concreting condition), 6, 12, 24 and 72 hours. In the case of concreting with no waiting time, the results are compared with the indirect tensile strength determined by diametral compression tests. The results allow to confirm the reliability of the method and provide experimental information that shows the influence of the waiting time between layers, or maturity of the joint, in the tensile strength of the joint.
\end{abstract}

Keywords - Concrete Roller Compacted (RCC) * Dams * Tensile Strength Direct Joints.

\section{Introduction}

The analysis of the result of the direct tensile tests carried out on cylindrical specimens of RCC with a new method developed at the Institute of materials and soils of the Faculty of Engineering is presented in this work. The technique and developed procedure constitutes a valuable contribution to the study of the tensile strength of the RCC dam's construction joints. The tensile strength of the joints concrete between layers is a parameter of particular importance in the design of dams built using RCC technology. The application of this constructive method generates the formation of joints of concrete whose separation varies, depending on the thickness of the layers, between 30 and $45 \mathrm{~cm}$ and make up a system of parallel planes of potential structural weakness.

Under the seismic action the joints are subjected to tensile stress whose magnitude can overcome the resistance of the same and produce cracks that, depending on their magnitude, may be able to affect both the permeability and the structural integrity of the dam.

In the technical paper E 1110-2-2006 the USACE [1] and [2], establishes reference values for the tensile strength of joints for RCC dams, which are useful for applications at the draft.

In the case of little workable mixtures, (times older than 30 seconds consistency Vebe test) and maximum sizes of aggregates smaller than $75 \mathrm{~mm}$, the values of tensile strength of joints, recommended in this document, vary between 3 and $6 \%$ of the compressive strength, in the case of joints treated with mortar, and between 1.5 and $3 \%$ for untreated joints.

In the case of mixtures workable (times minor of 30 seconds in the trial of consistency Vebe) this relationship varies between the 4 and the $9 \%$ both for together treated as without treat. While these values serve as reference, for the project final of dams is essential to determine or verify experimentally that resistance.

This paper describes a test method developed at the Materials and soils Institute of the San Juan National University (IMS-UNSJ), which enables you to determine the strength of joints of concrete mixtures of RCC in direct tensile. Describes the characteristics of the test procedure and equipment, and presents test results for concrete made with different mixtures of RCC produced with pozzolanic cement with content ranging between 85 and $140 \mathrm{~kg} / \mathrm{m}^{3}$.

As variable of study it was considered joints treated with and without mortar and different times of expected for the concreting of the joint and the next layer.

The following sections describes the test device used to measure the tensile strength of joints of concrete, materials and tested mixtures are presented, are exposed and analyzed the results and presented the conclusions reached.

\section{J. O. Morand}

Universidad Nacional de San Juan

Materials and Soils Institute

Argentina

\section{R. J. Uliarte}

Universidad Nacional de San Juan Materials and Soils Institute

Argentina

\section{Tests carried out}

\section{A. Device's Test of Joints.}

In the scheme of the figure 1 is shows a sketch of the device used for the realization of those test of Direct Tensile Strength of joints of layers of RCC.

The device was designed to test of cylindrical specimens of $20 \times 40 \mathrm{~cm}$. It consists of 4 bodies or metallic helmets of semi-cylindrical shape and identical dimensions which are attached laterally to the specimen free leaving a central strip of between 5 and $7 \mathrm{~cm}$ thick, precisely in correspondence with the joint of concrete located in the central section of the specimen. 
Proc. of the Fifth International Conference on Advances in Civil, Structural and Environmental Engineering - ACSEE 2017. Copyright $($ Institute of Research Engineers and Doctors. All rights reserved.

ISBN: 978-1-63248-122-1 doi: 10.15224/ 978-1-63248-122-1-11

The inside of the helmet is upholstered with a pad of neoprene, $0.5 \mathrm{~cm}$ thick that covers the entire interior surface and

the

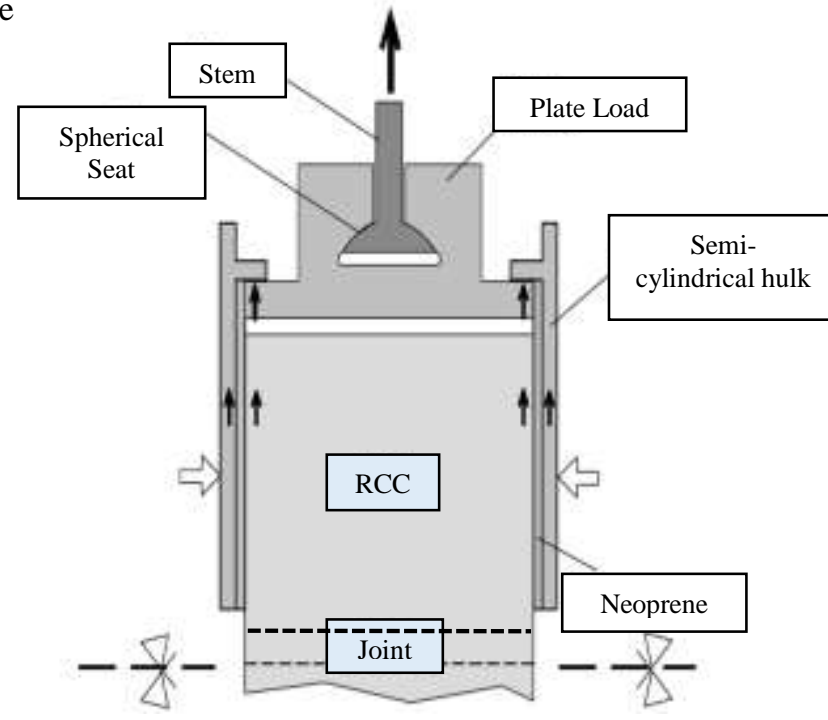

Figure 1. Sketch of the Joint direct tensile test device.

Helmets have a radius of curvature of $11 \mathrm{~cm}$, a wall of an approximate length of $20 \mathrm{~cm}$ and $1 \mathrm{~cm}$ thick. At the ends in correspondence with the cylinder heads, helmets have an inner ring, in which seat in one each plates of charge transfer. These plates are circular and in the centre a spherical seat which houses a stem of circular cross-section of $20 \mathrm{~mm}$ diameter that is linked to the jaws of the test machine.

Thus materializes a kneecap that ensures the alignment of the load. As you can see in the diagram of Figure 1, the efforts of traction is transferred along the lateral surface of the test piece, producing a state of uniform tensile stresses in the concrete located in the central section joint.

In the figure 2 is displayed photos of the device of test and of the specimens. In the photo top left is can observe a detail of two of them helmets abutments that is assembled laterally in them specimens of essay and of one of them plates of load with its respective stem of berth that is links to them jaws of the machine of essay.

In the picture on the right you can see a sample being tested and a cutting of a part of the device. The bottom picture shows a specimen in the test part of the mounted device machine.
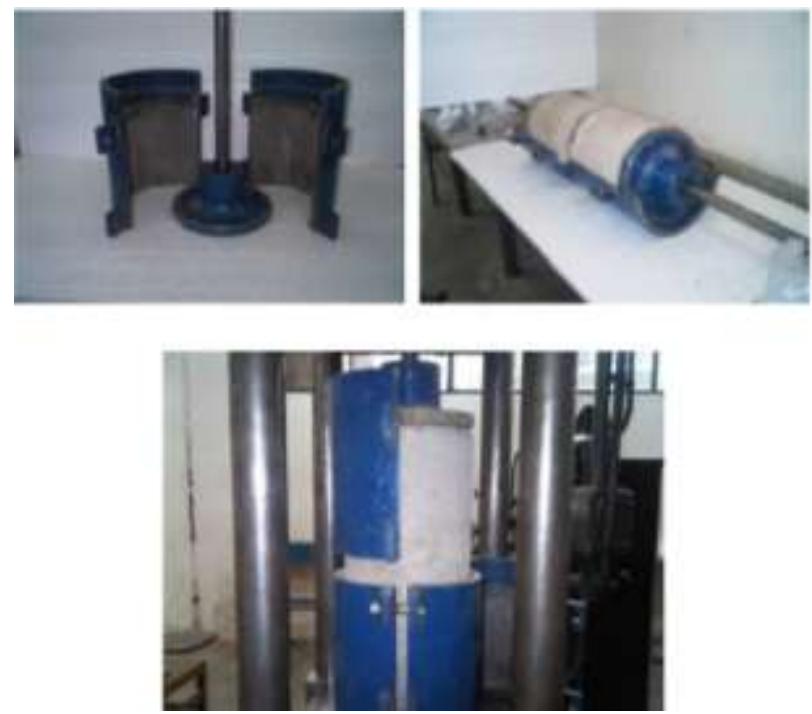

Figure 2. Photos of the device's test of Direct Tensile Strength of the RCC Joints

\section{B. Materials and Mixtures.}

The development of RCC mixtures used in the trials of joints were used in two different resistant class pozzolanic cements, CPP-30 and CPP-40, according to the standard IRAM 50,000, added thicknesses of crushing and natural sands. Both units were from alluvial deposits of fluvial origin. Table 1 shows properties of the aggregates used reference.

\begin{tabular}{|l|c|c|c|}
\hline \multirow{2}{*}{ Propiedades } & \multirow{2}{*}{ Norma } & \multicolumn{2}{c|}{ Values } \\
\cline { 3 - 4 } & IRAM & Fine Aggregate & Coarse Aggregate \\
\hline Relative Density & 1520 & 2,69 to 2,70 & 2,64 to 2,70 \\
\hline Absortion [\%] & 1520 & 0,70 to 1,70 & 0,39 to 0,45 \\
\hline Unit Weight [gr/cm ${ }^{3}$ ] & 1548 & 1,70 to 1,73 & 1,53 to 1,67 \\
\hline Modulus of fineness & 1505 & 2,90 to 3,05 & ---- \\
\hline Total Soluble Salts [\%] & 1647 & 0,04 to 0,61 & 0,009 to 0,018 \\
\hline Sulfate [\%] & 1647 & ND & ND \\
\hline Pass \#200 [\%] & 1540 & 3,50 to 12,10 & 1,2 to 2,50 \\
\hline Organic Material [p.p.m] & 1647 & $<500$ & ---- \\
\hline Carbonaceous Material [\%] & 1647 & 0,50 to 0,60 & 0,10 to 0,20 \\
\hline Clods of clay and crumbly particles & 1647 & 0,70 to 0,90 & 0,20 to 0,30 \\
\hline Los Angeles Wear [\%] & 1532 & ---- & 22 to 24 \\
\hline Accelerated reactivity test [\%] & 1674 & $<0,10$ & $<0,10$ \\
\hline Durability Sodium Sulfate [\%] & 1525 & 9 & 2,5 to 5,7 \\
\hline
\end{tabular}

Table 1. Properties of coarse and fine aggregates.

With them materials described previously is dosed 7 mixes of RCC, with different content of cement, that were employed to materialize the joint of concrete subject to trial. In the table 2 is described the proportions of them mixtures indicating in each case them content of added, water and cement necessary for develop $1 \mathrm{~m} 3$ of concrete compacted. It includes also the reference of the type of cement used.

\begin{tabular}{|c|c|c|c|c|c|c|c|}
\hline \multirow{3}{*}{ Mixture } & \multicolumn{4}{|c|}{ Coarse Aggregate $\left[\mathrm{kg} / \mathrm{m}^{3}\right]$} & \multirow{3}{*}{$\begin{array}{l}\text { Cement } \\
{\left[\mathrm{kg} / \mathrm{m}^{3}\right]}\end{array}$} & \multirow{3}{*}{$\begin{array}{c}\text { Water } \\
{[\mathrm{kg} / \mathrm{m} 3]}\end{array}$} & \multirow{3}{*}{$\begin{array}{l}\text { Type of } \\
\text { Cements }\end{array}$} \\
\hline & $38-63$ & $19-38$ & jun-19 & Sand & & & \\
\hline & $\mathrm{mm}$ & $\mathrm{mm}$ & $\mathrm{mm}$ & Natural & & & \\
\hline 1 & 418 & 392 & 442 & 930 & 120 & 132 & CPP30 \\
\hline 2 & 459 & 459 & 563 & 833 & 100 & 105 & CPP30 \\
\hline 3 & ---- & $815^{(*)}$ & 591 & 862 & 120 & 120 & CPP30 \\
\hline 4 & 485 & 507 & 265 & 949 & 100 & 135 & CPP40 \\
\hline 5 & 494 & 517 & 270 & 966 & 85 & 128 & CPP40 \\
\hline 6 & 492 & 514 & 268 & 961 & 120 & 135 & CPP30 \\
\hline 7 & 480 & 480 & 262 & 960 & 140 & 132 & CPP30 \\
\hline
\end{tabular}

Table 2. Proportions of mixtures of RCC

Note: (*) maximum size $50 \mathrm{~mm}$

\section{Laboratory Tests.}

To perform the tests of traction of the joints, with each of the mixtures described in Table 2, are molded cylindrical specimens of $20 \times 40 \mathrm{~cm}$ which were filled and compacted in 4 layers of $10 \mathrm{~cm}$ thick each. The compaction of the layers is made ramming the concrete with a mass of $10 \mathrm{~kg}$ applied through a percussion hammer of drive electric during a time of compaction of 20 to 25 seconds. The contact surface between the second and the third layer, located in the central section of the specimen, constitutes the 
Proc. of the Fifth International Conference on Advances in Civil, Structural and Environmental Engineering - ACSEE 2017. Copyright (C) Institute of Research Engineers and Doctors. All rights reserved.

ISBN: 978-1-63248-122-1 doi: 10.15224/ 978-1-63248-122-1-11

Joint subjected to trial. It molding of the joints contemplated conditions of concrete continuous, without delays in them times of compaction of the different layers, and conditions of concreting discontinuous. In the latter case after compacting the first two layers of concrete was intentionally delayed the concreting of the two remaining layers, causing an open time of the Joint that ranged from 6 to 72 hours.

While the open joints remained exposed to laboratory environment. Regarding the treatment of the joints is contemplated by two conditions: joints without trying and joints treated with mortar. The mortar consisted of a mix ratio water/cement by weight of 0.80 and sand/cement by weight of 4.9 which applied at a thickness of $2 \mathrm{~cm}$ on the entire surface of the joint. This application is performed immediately before the placement of the layer of concrete that covers the joint

For each mixture, molding and treatment of joints conditions are shaped and rehearsed between 4 and 6 cylinders at an age that varied between 28 and 90 days. The specimens are kept in their molds and in environment of laboratory during the first 7 days of age. Subsequently be proceeded to the unmolding of them same and to its storage low water saturated in lime to a temperature of curing of 23 $\pm 2{ }^{\circ} \mathrm{C}$. The specimens were kept in these conditions until the age of trial.

In addition are molded specimens of $20 \times 40 \mathrm{~cm}$ for testing simple compression and diametral compression according to rules IRAM 1546 and 1658. The specimens are kept 48 hours of age in laboratory environment and then stored under water in the same conditions as specimens for testing of joints. From these trials were determinations of compressive strength, resistance to the indirect tensile and modulus of elasticity according to the recommendations of the standard ASTM C 469.

\section{Results of the Tests.}

\section{D.1. Characterization tests of RCC mixtures.}

Table 3 shows the results of compressive strength, modulus of elasticity and indirect tensile strength of the concrete corresponding to the mixtures used for joint molding. The reported results correspond to the average of 6 test results.

\begin{tabular}{|c|c|c|c|c|c|c|}
\hline \multirow{2}{*}{ Mixture } & \multirow{2}{*}{$\begin{array}{c}\text { CUC } \\
{\left[\mathrm{kg} / \mathrm{m}^{3}\right]}\end{array}$} & Maximum & Test & Compressive & Modulus of & \multirow{2}{*}{$\begin{array}{c}\text { Direct-drive } \\
\text { traction [Mpa] }\end{array}$} \\
\cline { 3 - 6 } & & Size & Age & Strength & Elasticity & \\
\hline 1 & 120 & 65 & 90 & 11,3 & 13,1 & 1,3 \\
\hline 2 & 120 & 65 & 60 & 9 & 13,2 & 1,23 \\
\hline 3 & 120 & 50 & 60 & 10,8 & 16,8 & 1,48 \\
\hline 4 & 100 & 65 & 28 & 7,1 & 12,5 & 0,89 \\
\hline 5 & 85 & 65 & 28 & 5,4 & 11 & 0,71 \\
\hline 6 & 120 & 65 & 28 & 8,4 & 13,3 & 0,95 \\
\hline 7 & 140 & 65 & 28 & 10 & 16,4 & 1,15 \\
\hline
\end{tabular}

Table 3. Properties of mixtures.

Depending on the contents of cement and ages of test concretes tested presented values of compressive strength ranging between 5.7 and $11.3 \mathrm{MPa}$ and of indirect tensile strength ranging from 0.71 to $1.48 \mathrm{MPa}$. With respect to the modulus of elasticity values obtained ranged from 11.0 to $16.8 \mathrm{GPa}$. These parameters are typical values in HCR mixtures used in the construction of dams.

\section{D.2. Direct tensile tests of joints.}

Table 4 shows, for different mixtures of RCC, treatment of joints and waiting times, the results of direct tensile strength of the tested joint, ftdj. The Table also includes the results of the tensile strength of the joint in relation to the strength of the concrete, $\mathrm{fti}$, and resistance to compression at f c.

\begin{tabular}{|c|c|c|c|c|c|}
\hline Mixture & $\begin{array}{l}\text { Wait } \\
\text { time }\end{array}$ & $\begin{array}{l}\text { Seat } \\
\text { Mortar }\end{array}$ & $f_{\text {tdj }}$ & $f_{\mathrm{tdj}} / f_{\mathrm{ti}}$ & $f_{\mathrm{tdj}} / f^{\prime}{ }_{\mathrm{c}}$ \\
\hline $\mathrm{N}^{\circ}$ & {$[\mathrm{hs}]$} & & {$[\mathrm{Mpa}]$} & & \\
\hline \multirow{5}{*}{1} & 0 & $\mathrm{NO}$ & 0,66 & 0,51 & 0,06 \\
\hline & 12 & NO & 0,26 & 0,2 & 0,02 \\
\hline & 12 & SI & 0,6 & 0,46 & 0,05 \\
\hline & 18 & NO & 0,19 & 0,115 & 0,02 \\
\hline & 72 & SI & 0,62 & 0,48 & 0,05 \\
\hline \multirow{5}{*}{2} & 0 & $\mathrm{NO}$ & 0,59 & 0,48 & 0,07 \\
\hline & 6 & $\mathrm{NO}$ & 0,3 & 0,24 & 0,03 \\
\hline & 6 & SI & 0,66 & 0,54 & 0,07 \\
\hline & 72 & $\mathrm{NO}$ & 0,17 & 0,14 & 0,02 \\
\hline & 72 & SI & 0,76 & 0,62 & 0,08 \\
\hline \multirow{5}{*}{3} & 0 & NO & 0,78 & 0,53 & 0,07 \\
\hline & 6 & $\mathrm{NO}$ & 0,76 & 0,51 & 0,07 \\
\hline & 6 & SI & 0,82 & 0,55 & 0,08 \\
\hline & 72 & $\mathrm{NO}$ & 0,33 & 0,22 & 0,03 \\
\hline & 72 & SI & 1,06 & 0,72 & 0,1 \\
\hline 4 & 0 & $\mathrm{NO}$ & 0,48 & 0,54 & 0,07 \\
\hline 5 & 0 & NO & 0,46 & 0,65 & 0,08 \\
\hline 6 & 0 & NO & 0,6 & 0,63 & 0,07 \\
\hline 7 & 0 & $\mathrm{NO}$ & 0,68 & 0,59 & 0,07 \\
\hline
\end{tabular}

Table 4. Results of tensile strength of joints of HCR.

Figure 3 shows the relative values of the direct tensile strength of joints moulded continuously (wainting time $=0$ ) referred to indirect tensile strength of the concrete. In the same figure shown in dashed line reference value recommended in the technical paper E 1110-2-2006 the USACE in the case of joints constructed with mixtures of RCC workable consistency (the Vebe test times < 30 seconds). The plotted values show that tested joint had a tensile strength that ranged from 48 to $65 \%$ of the concrete indirect tensile strength, values that are reasonably in correspondence with the value recommended by the USACE.

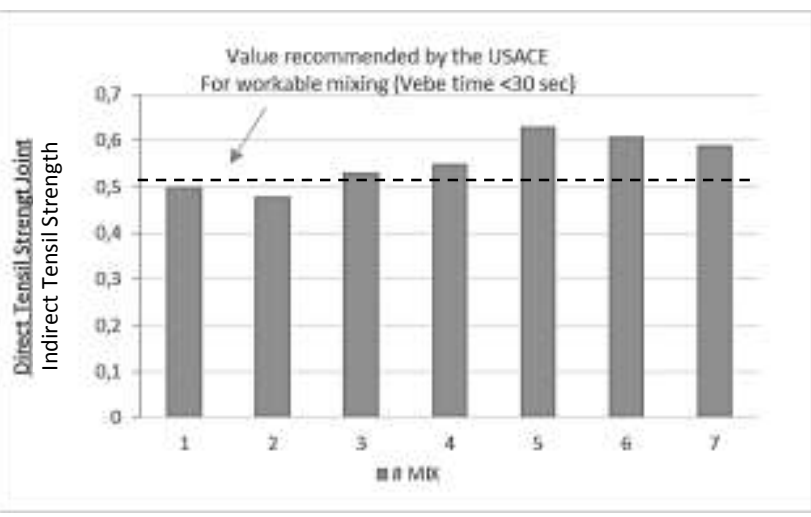

Figure 3. Ratio of joints direct tensile strength of concrete (joints without mortar and concrete continuous) indirect tensile strength. 
Proc. of the Fifth International Conference on Advances in Civil, Structural and Environmental Engineering - ACSEE 2017. Copyright (@) Institute of Research Engineers and Doctors. All rights reserved.

ISBN: 978-1-63248-122-1 doi: 10.15224/ 978-1-63248-122-1-11

Figure 4 shows the relative values of the direct tensile strength of joints moulded continuously (timeout $=0$ ) referred to the resistance to compression of concrete. In the same figure is displayed in lines of strokes the range of variation preferred in the mentioned document of the USACE for the case of joints built with mixtures of RCC of consistency workable. The plotted values show that joint tested had a tensile strength that ranged between 6 and $8 \%$ of the concrete compressive strength, values that are within the range recommended by the USACE.

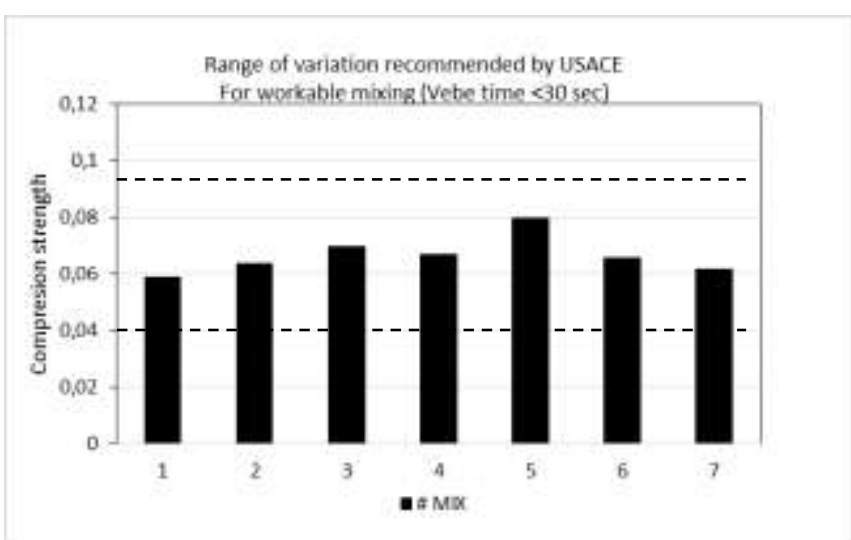

Figure 4. Relationship between joints of direct tensile strength and resistance to compression of concrete (joints withut mortar and continuous concreting).

In Figure 5 the results of the relative resistance to traction of the joints according to the time of waiting for the concreting of the joints are represented. Resistance value corresponding to the continuous concreting of the joints has been adopted as a reference for the construction of the graph. The plotted results show that you for the case of joints treated with mixture, the waiting time in the concreting of the joints produced no significant deterioration of its tensile strength, observing an increase in resistance in some mixtures of the joint with the waiting time. For untreated joints was observed for higher wait times that 6 hours there was a significant reduction in the strength of the joint observed an increase in loss of resistance with the waiting time as trend. In this case the strength values of the joints varied between 29 and $42 \%$ of the value corresponding to the strength of the concreted joint continuously.

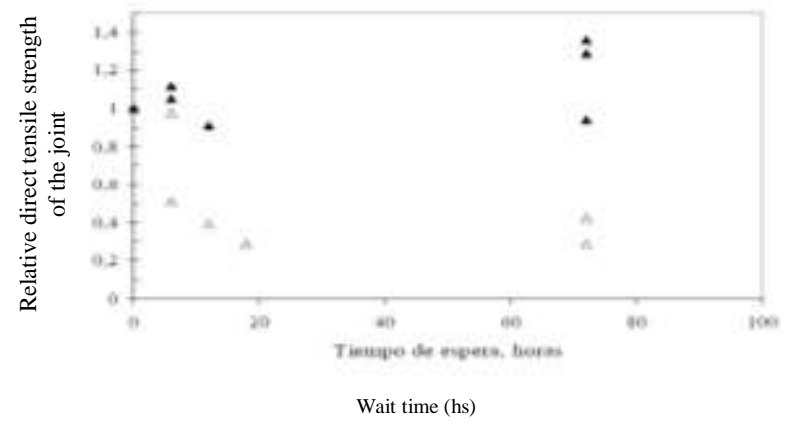

Figure 5. Relative resistance direct tensile joints concrete with different timeout.

\section{5) Conclusions}

The results obtained in the present work allow the following conclusions to be drawn:

a. A direct traction test procedure has been developed which can be used to objectively and reliably characterize the tensile strength of concrete joints in roller compacted concrete mixtures.

b. The results of the joints tested, corresponding to 7 mixtures of RCC made with different cement contents, showed that the continuously mixed concretes presented values of direct tensile strength between 48 and $65 \%$ of the resistance to Indirect traction or between 6 and $8 \%$ of the compressive strength of the concrete. These values are compatible with the reference values recommended by the US Army Corps of Engineers in the Engineer Manual M 1110-2-2006.

c. Regarding the incidence of the waiting time in the concreting of the joint the results showed that in the case of joints not treated with mortar mix, a delay of 6 to 72 hours in the concreting of the joint produces a loss of resistance at tensile of between 50 and $70 \%$.

\section{References}

[1] Roller Compacted Concrete Engineer Manual M 1110-2-2006. US Army Corps of Engineers.

[2] CANNON, ROBERT W. (1995) - Seismic Design Provisions for Roller Compacted Concrete Dams; Appendix E, Tensile Strength of Roller Compacted Concrete, Engineer Pamphlet 1110-2-12, U.S. Army Corps of Engineers

[3] ROCCO, MORANDI, FAVA, GIOVAMBATTISTA (2010) Resistencia a la tracción de juntas de hormigón compactado a rodillo en presas, Congreso Internacional de Tecnología del Hormigón, Mar del Plata - Argentina.

[4] Roller-Compacted Mass Concrete. ACI Committee 207.

[5] Standard Test Method for Direct Tensile Strength of Cylindrical Concrete or Mortar Specimens. CRD-C 164-92.

[6] STRUCTURAL DESIGN USING THE ROLLER-COMPACTED CONCRETE (RCC) CONSTRUCTION PROCESS. ETL 1110-2343-93.

About author (s):

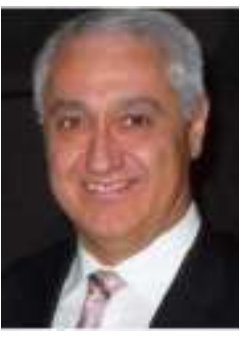

M. Cs. Ing. Civil Javier O. Morandi.

Researcher Materials and Soils Institute. San Juan National University Argentina 